University of Nebraska - Lincoln

DigitalCommons@University of Nebraska - Lincoln

2018

Reproductive promiscuity in the variegated fairy-wren: An alternative reproductive strategy in the absence of helpers?

\author{
Allison E. Johnson \\ University of Nebraska-Lincoln, ajohnson165@unl.edu \\ Stephen Pruett-Jones \\ The University of Chicago, pruett-jones@uchicago.edu
}

Follow this and additional works at: https://digitalcommons.unl.edu/bioscifacpub

Part of the Biology Commons, and the Ornithology Commons

Johnson, Allison E. and Pruett-Jones, Stephen, "Reproductive promiscuity in the variegated fairy-wren: An alternative reproductive strategy in the absence of helpers?" (2018). Faculty Publications in the Biological Sciences. 863.

https://digitalcommons.unl.edu/bioscifacpub/863

This Article is brought to you for free and open access by the Papers in the Biological Sciences at DigitalCommons@University of Nebraska - Lincoln. It has been accepted for inclusion in Faculty Publications in the Biological Sciences by an authorized administrator of DigitalCommons@University of Nebraska - Lincoln. 


\title{
Reproductive promiscuity in the variegated fairy-wren: An alternative reproductive strategy in the absence of helpers?
}

\author{
Allison E. Johnson ${ }^{1} \&$ Stephen Pruett-Jones ${ }^{2}$ \\ 1 School of Biological Sciences, University of Nebraska-Lincoln, NE, U.S.A. \\ 2 Department of Ecology and Evolution, University of Chicago, Chicago, IL, U.S.A. \\ Correspondence - A. E. Johnson, School of Biological Sciences, University of Nebraska- \\ Lincoln, Manter Hall 406, 1104 T Street, Lincoln, NE 68588, U.S.A. \\ Email — A. E. Johnson, aj.petrochelidon@gmail.com \\ S. Pruett-Jones, pruett-jones@uchicago.edu
}

\begin{abstract}
Cooperative breeding, in which auxiliary group members help rear related, but nondescendent young, is often explained by kin selection. Reproductive monogamy is predicted in cooperatively breeding systems, as monogamy increases intragroup relatedness and maximizes auxiliary inclusive fitness. While monogamy is observed across many systems, including eusocial insects and cooperatively breeding mammals, some cooperatively breeding birds exhibit high rates of extrapair paternity. Here we quantify paternity and examine the role of auxiliaries on extrapair paternity in the highly cooperative variegated fairy-wren, Malurus lamberti, a species with both male and female auxiliaries. Extrapair paternity occurred in $55.4 \%$ of nests, and $39.8 \%$ of offspring were the result of extrapair matings. The presence of both male and female auxiliaries had a positive relationship with the percentage of within-pair young sired by
\end{abstract}

Published in Animal Behaviour 139 (2018) 171-180

doi:10.1016/j.anbehav.2018.03.015

Copyright (C) 2018 The Association for the Study of Animal Behaviour. Published by Elsevier

Ltd. Used by permission..

Submitted 23 August 2017; accepted 26 February 2018; published 26 April 2018. 
dominant males, however, the presence of male auxiliaries had a stronger impact than the presence of females. The number of extrapair young sired by dominant males decreased as the number of male auxiliaries increased. The total number of young sired by dominant males, however, was not predicted by group size or relatedness to their social partner, nor did group composition or relatedness to the breeding pair predict the reproductive success of subordinate males. We hypothesize that breeders use alternative reproductive strategies in the presence or absence of auxiliaries. Males and females may seek extrapair reproductive opportunities when no help is available in their group and nest survival is expected to be low. When help is available, breeders may reduce extrapair paternity, either to increase intragroup relatedness or because confidence in nest survival is high. Our data suggest that group composition is important in understanding extrapair paternity rates in cooperatively breeding birds and that variation in extrapair paternity rates may be the result of flexible breeding strategies when auxiliary presence and identity varies.

Keywords: cooperative breeding, extrapair, paternity, helping behavior, kin selection, Malurus, mate choice, reproductive strategy

Cooperative breeding is characterized by delayed dispersal of one or both sexes and alloparental care by auxiliary group members (Brown, 1987; Emlen, 1991). Historically, inclusive fitness theory has been used to explain the evolution of cooperative societies, both in vertebrate and nonvertebrate systems (Browning, Patrick, Rollins, Griffith, \& Russell, 2012; Hamilton, 1964; Hatchwell, Gullett, \& Adams, 2014; West, Griffin, \& Gardner, 2007). This theory asserts that inclusive fitness gained by contributing to the raising of putative siblings can outweigh the costs of helping behavior by auxiliaries and the benefits of independent breeding (Fitzpatrick \& Bowman, 2016; Koenig, Pitelka, Carmen, Mumme, \& Stanback, 1992; Mumme, 1992; MacColl \& Hatchwell, 2002). It is predicted, and generally supported, that the evolution of cooperative breeding behavior is linked to reproductive monogamy and high intragroup relatedness (Boomsma, 2013; Cornwallis, West, Davis, \& Griffin, 2010; Lukas \& Clutton-Brock, 2012). In insects, the evolution of eusociality in many taxa is associated with strict monogamy (Boomsma, 2009), and in cooperatively breeding mammals a single male is responsible for most of the offspring in a social group, varying from $76 \%$ to $100 \%$ across taxa (Griffin et al., 2003; Lukas \& Clutton-Brock, 2012).

Many cooperatively breeding avian taxa conform to expectations of monogamy, such as red-cockaded woodpeckers, Picoides borealis, or chestnut-crowned babblers, Pomatostomus ruficeps, in which only $0-1 \%$ 
of young are sired by extrapair males (Haig, Belthoff, \& Allen, 1993; Haig, Walters, \& Plissner, 1994; Russell, 2016). However, some cooperatively breeding avian species exhibit high rates of extrapair paternity, such as the superb fairy-wren, Malurus cyaneus, which has up to $76 \%$ of young sired by extrapair males (Mulder, Dunn, Cockburn, Lazenby-Cohen, \& Howell, 1994).

Helping behavior across avian taxa has been shown to correlate positively with auxiliary relatedness to the nestlings they are providing care to, supporting a leading role for kin selection in either the evolution or maintenance of cooperative breeding in birds (Green, Freckleton, \& Hatchwell, 2016). Explaining the variation in reproductive promiscuity present in cooperatively breeding birds has been the subject of much research, as it does not conform to the expectations of a kin-selected explanation for cooperative breeding, causing auxiliaries to invest in unrelated young to themselves (Dunn, Cockburn, \& Mulder, 1995). When auxiliaries are sons or daughters of the breeding pair, promiscuity can decrease the relatedness of auxiliaries to the nestlings they are rearing by $50 \%$. Furthermore, if the mother of the auxiliaries has been replaced, and an unrelated female gains the breeding vacancy, auxiliaries may be unrelated to all offspring produced by extrapair copulations.

Fairy-wrens (Maluridae) were among the first documented cooperatively breeding birds (Boland \& Cockburn, 2002), and since this discovery, every species in the genus Malurus that has been studied has been documented as breeding cooperatively (e.g. Brouwer, van de Pol, Atema, \& Cockburn, 2011; Dunn \& Cockburn, 1996; Kingma, Hall, Segelbacher, \& Peters, 2009; Pruett-Jones \& Tarvin, 2001; Rowley \& Russell, 1995; Tidemann, 1983). While fairy-wrens serve as models for research on cooperative breeding, they are also atypical because of their extremely high rates of extrapair paternity (varying from 4\% to $76 \%$ ). Rather than linking helping behavior to monogamy as expected and observed in many cooperative breeders (Green et al., 2016), the presence of auxiliaries has been correlated with increased rates of extrapair paternity in at least four fairy-wren species (Brouwer et al., 2017; Mulder et al., 1994; Webster, Tarvin, Tuttle, \& Pruett-Jones, 2004). It has been suggested that the presence of auxiliaries liberates breeding females to engage in extrapair copulations by ensuring help at the nest and buffering any possible retaliatory reduction in the investment of the dominant male (Mulder et al., 1994). However, similar 
rates of extrapair paternity have been observed in superb fairy-wren populations with both high and low numbers of auxiliaries (Colombelli-Négrel, Schlotfeldt, \& Kleindorfer, 2009), and males of the redbacked fairy-wren, Malurus melanocephalus, have not been found to reduce parental investment in nests with extrapair young (Varian-Ramos, Lindsay, Karubian, \& Webster, 2012). These findings suggest that there are additional factors besides female liberation influencing extrapair paternity in this family, for example inbreeding avoidance, amount of help received or population density (Cockburn, Brouwer, Double, Margraf, \& van de Pol, 2013; Brouwer et al., 2017).

Here we investigate rates of extrapair paternity in one of the most social of the fairy-wren species, the variegated fairy-wren, Malurus lamberti. In the variegated fairy-wren, auxiliaries show extreme variation in number (from 0 to 8 in some populations: D. Thrasher, personal communication), sex and contribution (Johnson, 2016). In general, delayed dispersal and helping behavior in birds is more common in male auxiliaries (Cockburn, 1998; Cornwallis, West, \& Griffin, 2009). However, in variegated fairy-wrens nearly half of all auxiliaries are female $(\sim 43 \%$ in our population). While both sexes perform helping behaviors, male auxiliaries provision nestlings at a higher rate than females $(2.29$ feeds/h and 0.52 feeds/ h, respectively) and only $11 \%$ of male auxiliaries have been observed to not provision, whereas up to $31 \%$ of female auxiliaries do not provision (Johnson, 2016; Johnson \& Pruett-Jones, 2017). This system provides a unique opportunity to examine the role not only of group size, but also of group composition on extrapair paternity.

\section{Methods}

\section{Study System and Field Methods}

This research was conducted at Brookfield Conservation Park (BCP) from 2012 to 2015. BCP, located in South Australia (S 34²1', E 139²9'), is a 5534 ha park characterized by mallee eucalyptus scrub forest and chenopod scrub habitat and supports populations of three species of fairy-wren, the variegated fairy-wren, the splendid fairy-wren, Malurus splendens, and the white-winged fairy-wren, Malurus leucopterus (Department for Environment and Heritage, 2005; Tibbetts \& Pruett-Jones, 
1999). Variegated fairy-wrens were mostly found within the mallee scrub often co-occurring with splendid fairy-wrens (Johnson, 2016; Tibbetts \& Pruett-Jones, 1999).

Each year we surveyed family groups of variegated fairy-wrens from mid-September until late December. This time period encompassed the majority of breeding attempts; however, some nesting attempts were observed at the end of the field season, suggesting that some breeding likely occurs in January, as seen in the splendid fairy-wren (Van Bael \& Pruett-Jones, 2000).

A color-banded population of variegated fairy-wrens was established at this site in 2012. Adult birds were captured by targeted mist netting, a method that minimizes bicatch and the duration of time birds are left alone in the net unattended. Adults were banded with a unique combination of three color bands and an individually numbered metal band issued by the Australian Bird and Bat Banding Scheme. We determined the age of birds when possible. Birds that were captured and banded as juveniles were of known age, while unbanded males could often be aged to 1 year if they exhibited partial plumage or if their bill color had not yet changed from brown to black. In male variegated fairy-wrens as in some other species of fairy-wrens, the color of the bill changes from brown to black at approximately 1 year of age, after which it remains black (Rowley \& Russell, 1997; A. E. Johnson, personal observation). While some first-year males exhibit adult plumage, many exhibit either female-like plumage or partial mature plumage. Such delayed plumage maturation is also observed in other fairy-wren species (Karubian, 2002; Rathburn \& Montgomerie, 2003; Rowley \& Russell, 1997; Webster, Varian- Ramos, $\&$ Karubian, 2008). At the time of capture, morphological measurements were taken, and a blood sample was taken by brachial vein puncture and stored dry on Whatman ${ }^{\circledR}$ FTA cards for later DNA extraction.

Once individuals were color banded, they could be assigned to groups that were then monitored for composition, nesting behavior and territory size. Each year between 37 and 70 family groups were studied. Family groups contained at least one male and one female, but groups often contained auxiliary group members. Auxiliaries are often referred to as 'helpers' throughout cooperative breeding literature. In the variegated fairy-wren, auxiliary members of both sexes do help in provisioning young, among other behaviors. However, individuals and sexes vary in the degree of helping behavior, and because we do not quantify 
helping behavior of individuals here, we refer to these group members as 'auxiliaries'. The largest observed social group in our population contained seven auxiliaries (total group size of 9). Mean group size varied between years from 2.91 to 4.24 , with $54.29 \%-75.68 \%$ of groups containing one or more auxiliary members. As with other fairy-wren species (Margraf \& Cockburn, 2013; Mulder et al., 1994; Varian-Ramos \& Webster, 2012; Webster et al., 2004), most auxiliary group members in our population were sons or daughters of one or both members of the breeding pair from previous years. Dominance status of males and females was determined by known age and plumage variation, or by behavior. Older males were observed to be dominant over younger males in the same group. Dominant males exhibited mate guarding of the female prior to egg laying. If not banded in the previous season, many auxiliary males could be distinguished from the dominant male by delayed plumage maturation. Similarly, males in full plumage were observed to be dominant over males in partial plumage. If auxiliary males could not be distinguished by plumage, they were distinguished either by behavior, or whether the dominant male was known to be the breeder in previous years. Lastly, dominant females were the first, or only, female to initiate breeding in a group. Similar criteria for determining dominance status were used by Webster et al. (2004) and Tarvin, Webster, Tuttle, and Pruett-Jones (2005).

Plural breeding was observed in a few groups, an observation consistent with other fairy-wren species (Brouwer et al., 2011; Rowley, Russell, Payne, \& Payne, 1989; Van Bael \& Pruett-Jones, 2000). Between 2012 and 2015, 5\% of territories exhibited plural breeding (11 of 220 social groups).

Groups were monitored weekly for nesting behavior, and once nests were found we monitored their fate. If nests successfully produced nestlings, blood samples were collected from the nestlings when they were between 3 and 8 days old and stored as described above. Nestlings that survived to 6 days old were banded with a metal band.

\section{Genotyping, Paternity and Relatedness}

DNA was extracted using a modified version of Qiagen's DNeasy Blood and Tissue Kit (Qiagen Inc., Valencia, CA, U.S.A.) protocol for extraction of DNA from whole blood or tissue samples. Individuals were genotyped 
using six highly polymorphic microsatellite loci originally developed for related fairy-wren species and optimized for use in the variegated fairywren (Table 1). Each locus was amplified using fluorescently-labelled primers and a standard PCR protocol. Samples were genotyped by the University of Chicago DNA Sequencing and Genotyping Facility and allele size determined with Peak Scanner ${ }^{\mathrm{TM}} 1.0$ (Applied Biosystems, Foster City, CA, U.S.A.) software. Raw peak sizes were binned to best fit the expected base pair repeat described for each locus. All alleles approximately matched the expected size, except for two alleles for Mcyu 8 and two alleles for Mcyu3 that were indistinguishable from one another and thus each binned into a single allele.

Cervus 3.0 (Kalinowski, Taper, \& Marshall, 2007; Marshall, Slate, Kruuk, \& Pemberton, 1998) was used to assess allele frequencies, estimate expected and observed heterozygosity, null allele frequency, and assign paternity. Analyses were completed for each year separately. The six microsatellites analyzed were highly variable with between 9 and 48 alleles (Table 1). One locus, Mcyu2 deviated significantly from HardyWeinberg equilibrium $(P<0.05)$ consistently across all 3 years, suggesting the presence of null alleles (Pemberton, Slate, Bancroft, \& Barrett, 1995). The presence of null alleles can influence mismatches between known parent-offspring pairs, resulting in typing errors. Cervus estimates null allele frequencies using the method described by Summers

Table 1 Description of microsatellite loci used in genotyping

\begin{tabular}{|c|c|c|c|c|c|c|c|c|c|c|}
\hline \multirow[t]{2}{*}{ Locus } & \multirow{2}{*}{$\begin{array}{l}\text { Optimized } \\
\text { annealing } \\
\text { temp. }\left({ }^{\circ} \mathrm{C}\right)\end{array}$} & \multirow[t]{2}{*}{ No. alleles } & \multicolumn{2}{|c|}{ Heterozygosity } & \multirow{2}{*}{$\begin{array}{c}\text { Maternal } \\
\text { exclusion } \\
\text { prob. }\end{array}$} & \multirow{2}{*}{$\begin{array}{c}\text { Paternal } \\
\text { exclusion } \\
\text { prob. }\end{array}$} & \multirow{2}{*}{$\begin{array}{l}\text { Null } \\
\text { allele } \\
\text { freq. }\end{array}$} & \multirow{2}{*}{$\begin{array}{c}\text { Genotyping } \\
\text { error } \\
\text { rate }\end{array}$} & \multirow{2}{*}{$\begin{array}{c}\text { Species } \\
\text { developed } \\
\text { in }\end{array}$} & \multirow[t]{2}{*}{ Source } \\
\hline & & & Obs. & Exp. & & & & & & \\
\hline Mcyu2 & 62 & 9 & $0.27^{\mathrm{a}}$ & 0.58 & 0.18 & 0.30 & 0.37 & $>0.01 \quad 1$ & Malurus cyaneus & Double et al. (1997) \\
\hline Msp10 & 65 & 17 & 0.83 & 0.84 & 0.53 & 0.69 & -0.001 & $>0.01$ & M. splendens & Webster et al. (2004) \\
\hline Smm7 & 54 & 19 & 0.9 & 0.89 & 0.63 & 0.77 & -0.008 & $>0.01$ & $\begin{array}{l}\text { Stipiturus } \\
\text { malachurus }\end{array}$ & $\begin{array}{l}\text { Maguire, Guay, and } \\
\text { Mulder (2006) }\end{array}$ \\
\hline Mcyu7 & 62 & 12 & 0.58 & 0.62 & 0.21 & 0.36 & 0.04 & $>0.01$ & M. cyaneus & Double et al. (1997) \\
\hline Mcyu8 & 62 & 48 & $0.90^{\mathrm{b}}$ & 0.95 & 0.81 & 0.89 & 0.02 & 0.01 & M. cyaneus & Double et al. (1997) \\
\hline Mcyu3 & 55 & 28 & $0.59^{\mathrm{b}}$ & 0.93 & 0.76 & 0.86 & 0.23 & 0.01 & M. cyaneus & Double et al. (1997) \\
\hline \multicolumn{2}{|c|}{ Combined } & & & & 0.99 & 0.99 & & 0.004 & & \\
\hline
\end{tabular}

The number of alleles is the total number observed across all years; all other statistics are based on 2012 adult samples (N 1/4 177 individuals, 162-176 individuals typed per locus). Maternal exclusion probability is the probability that a randomly selected candidate parent will not match the chick at a given locus when no parent genotype is known.

Paternal exclusion probability is the probability that a randomly selected candidate father will be excluded assuming the maternal genotype is known.

a. Significantly deviates from Hardy-Weinberg equilibrium (goodness-of-fit tests: $d f=1, P<0.05$ ).

b. Hardy-Weinberg equilibrium test not carried out due to the presence of alleles at a frequency of 5 or below. 
and Amos (1997). Low null allele frequencies $(<0.05)$ generally do not affect error rate. Two loci used in our analyses exhibited high null allele frequencies (Mcyu2 and Mcyu3), however, both loci were left in analyses because they exhibited a low genotyping error rate (Table 1). Two loci, Mcyu8 and Mcyu3 were not tested for deviation from Hardy-Weinberg due to the presence of alleles at a frequency of 5 or lower. While Cervus can complete Hardy-Weinberg equilibrium tests with low allele frequencies, the results must be interpreted with caution, and thus were not carried out. See Table 1 for summary of 2012 statistics.

High variability in the loci resulted in high exclusion probabilities. Across all years combined, maternal exclusion probability varied from 0.9915 to 0.9946 and paternal exclusion probability varied from 0.9992 to 0.9995 . Of the 397 offspring genotyped, 354 (89.17\%) had no allelic mismatches with the known mother, 37 (9.3\%) had one mismatch and $6(1.51 \%)$ had two mismatches. Nestling and mother pairs that differed at one locus were retained as most mismatches occurred at Mcyu3 or Mcyu 8 and could be explained by null alleles or were one repeat apart and may have been the result of mutation or genotyping error. Although we were confident in the identity of each nestling's mother, we excluded any nest in which one or more nestlings exhibited two or more mismatches with the presumed mother ( 5 nests) to avoid the possibility that the mother was misidentified or that brood parasitism did occur at a low rate. We chose to remove the whole nest rather than just the mismatching individuals in analyses of extrapair paternity rate to avoid inflating extrapair paternity and incorrectly identifying a nest as containing or not containing extrapair young. After excluding groups where one or more nestlings were not sampled (due to predation or death prior to sampling), second broods, nests of subordinate breeders and nests for which one or more nestlings had two mismatches with the social mother, a total of 120 nests (332 nestlings) were retained for subsequent paternity analysis.

Because egg laying by the breeding female was often observed and there were no instances of two females incubating the same clutch, we were highly confident in maternal identity (except in the cases described above) and therefore conducted paternity analysis given known mother identity. Cervus simulates paternity using the sampled population prior to paternity analysis. For each year, we used the following simulation parameters: proportion of candidate fathers sampled $=0.95$, proportion 
of loci typed $=0.978$, proportion of loci mistyped $=0.05$, error rate in likelihood calculations $=0.05$. Proportion of candidate fathers sampled was based on field observations and what percentage of the male population we believed that we sampled.

Cervus calculated a likelihood score (LOD score) for all males in the population given the genotype assigned for the mother, confidence of the LOD score of the candidate father, as well as of the trio (offspring, mother, father). Cervus assigned fathers to an average of $96 \%$ of offspring at a confidence of $80 \%$ across years. When Cervus did not assign confidence for any male, we accepted the male with the highest LOD score as the father if the male was the social father and had fewer than two mismatches.

We accepted the Cervus assignment for 271 (81.63\%) nestlings. For 45 nestlings, we accepted the social father in favor of the candidate father selected by Cervus because the social father had the same or fewer mismatches than the candidate. We accepted Cervus's second candidate for 11 nestlings because that male had the same or fewer loci mismatches as the first-ranked candidate but was also the assigned father for another nestling in that nest. For three nestlings, we accepted Cervus's second candidate because that male had the same or fewer mismatches and was a neighbor, and the assigned father was in a distant territory. For two nestlings in one nest we accepted no father assignment because they were outside the normal study area and we had not sampled many of the potential sires in that area; however, we assigned these as extrapair young because the social father had a low LOD score for both nestlings. In most cases, when another male was accepted over the male with the highest LOD score, the mismatch between the accepted male and the nestling was associated with the presence of a null allele (especially in Mcyu2 or Mcyu3). While the loci used had a high exclusion probability, the Cervus program may still misidentify potential fathers, particularly when candidate fathers are related (Double, Dawson, Burke, \& Cockburn, 1997), and these exceptions were designed to improve the accuracy of paternity assignment.

While paternity was assigned with confidence for most nestlings, in cases when no male was supported with a high confidence and the social male had a low LOD score, the nestling was identified as extrapair (not sired by the social father) even though paternity was not assigned. In this scenario, nestlings were excluded from analyses of paternity identity, but 
were included in analyses of extrapair paternity rates. One nest was excluded from paternity analysis because three or more mismatches occurred between the mother and one or more of her chicks, suggesting either misidentification of the mother or genotyping error.

We then calculated relatedness between adults to determine whether relatedness among breeding pairs or relatedness between auxiliary males and the breeding pair influenced mating behavior. Pairwise relatedness between individuals (all adults each year) was calculated using the program ML-Relate using allele frequency output from Cervus (Kalinowski, Wagner, \& Taper, 2006). The MLRelate program is specifically designed for microsatellite data and handles the presence of null alleles in its maximum likelihood estimates of relatedness.

\section{Statistical Analysis}

Statistical analyses were carried out in R 3.3.2 (R Development Core Team, 2016), using the package lme4 (Bates, Mächler, Bolker, \& Walker, 2015) as well as code developed by Nakagawa and Schielzeth (2013) to extract $R^{2}$ values from generalized linear mixed models (GLMMs). Within years, only the first nest of the dominant breeding female was retained for analysis. Additionally, we excluded nests of all auxiliary females $(N$ $=4$ ), as these females were never observed to receive help provisioning their nestlings from the dominant male and were observed to receive help only at a low frequency from other auxiliaries. Subordinate females, therefore, are not likely to be under the same constraints as the dominant breeder. We used a series of GLMMs to examine whether group composition influences extrapair paternity rates. First, we performed a GLMM with a binomial distribution to examine whether the probability that a clutch contained at least one extrapair young changed with fixed effects presence or absence of male auxiliaries, presence or absence of female auxiliaries, brood size and relatedness between the dominant male and female. We then used a GLMM with a binomial distribution weighted by brood size to examine whether the percentage of extrapair young in a nest varied with the same parameters, excluding brood size. For both analyses, year, breeding female identity nested within group identity (a variable that defines a particular territory space and therefore may account for some variation in territory quality) and breeding male identity nested within group identity were included in models as 
random effects. For both of these analyses, each group-year was considered an independent sample even though groups often persisted across years, because group composition frequently varied from year to year. We tested parameters of presence or absence of auxiliaries rather than number because within nests, the presence of auxiliaries has a stepwise effect on extrapair paternity within the nest (see Results).

To examine the role of group composition on male reproductive success, we performed four additional GLMMs. First, using a model with a binomial distribution weighted by brood size we examined the percentage of within-pair offspring sired by dominant males with respect to the fixed effects presence or absence of male auxiliaries, presence or absence of female auxiliaries and relatedness of the male to their social mate. This analysis is equivalent to the analysis examining the percentage of extrapair young within the nest, however, we chose to include this model for ease of interpreting male reproductive success. Second, using a model with a Poisson distribution, we examined the number of extrapair young sired by all dominant males with respect to the fixed effects number of male auxiliaries, number of female auxiliaries, number of within-group offspring sired and relatedness of the male to their social mate. Third, using a model with a Poisson distribution, we examined the total number of young (within-pair and extrapair) sired by dominant males with respect to the fixed effects number of male auxiliaries, number of female auxiliaries and relatedness of the male to their social mate. Finally, using a model with a Poisson distribution, we examined the number of total young (extragroup and intragroup) sired by all auxiliary males with respect to the fixed effects number of male auxiliaries, number of female auxiliaries and average relatedness to the breeding pair. For each model of male reproductive success, we included male identity, year and group identity as random effects. We binned the number of auxiliaries for graphical representation of the results, as few groups had more than three auxiliaries of either sex, but we analyzed the number of auxiliaries as an integer for all GLMMs. We selected models based on a stepwise backward elimination of nonsignificant terms in order of their $P$ value. In each final model, we retained only parameters with a $P$ value of $<0.15$ or the last parameter with the lowest $P$ value. Models were evaluated using Akaike's information criterion for small samples (AICc). 


\section{Ethical Note}

No experimental manipulations were conducted as a part of this research. While animals were captured for banding and to take blood samples, our netting procedures were designed to minimize the time the birds were in the net, and birds were released as soon as possible after processing. This research was conducted under approval from the South Australian authorities, University of South Australia Animal Ethics Committee (Wildlife Ethics Committee approvals 33/2015, 26/2015, 18/2012), South Australian Department of Environment, Water and Natural Resources (Scientific Research Permits U26057-4, U26057-3, U26057-2 and U26057-1), the University of Chicago Institutional Animal Care and Use Committee (ACUP permit number 72273) and the Australian Bird and Bat Banding Scheme (permit number 805).

\section{Results}

\section{Extrapair Paternity Rate and Role of Auxiliaries}

Across all years, 55\% of nests had one or more extrapair offspring, and $39.76 \%$ of sampled offspring were sired by an extrapair male (Table 2 ). of the 65 nests containing one or more extrapair young for which paternity was assigned, one extrapair male sired offspring in 36 (55.38\%) nests, two extrapair males sired offspring in 24 (36.92\%) nests and three extrapair males sired offspring in five (7.69\%) nests. For the 130 extrapair nestlings for whom paternity was assigned, 100 (76.92\%) were

Table 2 Summary statistics for genotyped clutches across years

\begin{tabular}{|c|c|c|c|c|c|c|c|}
\hline \multirow[b]{2}{*}{ Year } & \multicolumn{3}{|l|}{ Broods } & \multicolumn{2}{|l|}{ Nestlings } & \multicolumn{2}{|c|}{ Group characteristics } \\
\hline & $\begin{array}{l}\text { No. } \\
\text { analyzed }\end{array}$ & $\begin{array}{l}\text { No. containing } \\
\text { extrapair young } \\
(\% \pm 95 \% \mathrm{CI})\end{array}$ & $\begin{array}{l}\text { Average } \\
\text { brood size } \\
\text { (mean } \pm S D)\end{array}$ & $\begin{array}{l}\text { No. } \\
\text { genotyped }\end{array}$ & $\begin{array}{l}\text { Extrapair young } \\
(\% \pm 95 \% \text { CI })\end{array}$ & $\begin{array}{l}\text { Group size } \\
(\text { mean } \pm S D)\end{array}$ & $\begin{array}{l}\text { Mean group } \\
\text { sex ratio }\end{array}$ \\
\hline 2012 & 21 & $9(42.86 \pm 21.04)$ & $2.62 \pm 0.67$ & 55 & $18(32.73 \pm 12.05)$ & $4.52 \pm 2.02$ & 1.30 \\
\hline 2013 & 29 & $15(51.72 \pm 19.19)$ & $2.93 \pm 0.59$ & 85 & $34(40.00 \pm 10.48)$ & $3.24 \pm 1.21$ & 1.42 \\
\hline 2014 & 37 & $24(64.86 \pm 17.40)$ & $2.76 \pm 0.76$ & 102 & $47(46.08 \pm 9.92)$ & $3.12 \pm 1.07$ & 1.02 \\
\hline 2015 & 33 & $18(54.55 \pm 18.36)$ & $2.73 \pm 0.52$ & 90 & $33(36.67 \pm 9.91)$ & $3.12 \pm 1.66$ & 1.52 \\
\hline Total & 120 & $66(55.00 \pm 9.35)$ & $2.77 \pm 0.64$ & 332 & $132(39.76 \pm 5.30)$ & $3.39 \pm 1.42$ & 1.30 \\
\hline
\end{tabular}

Second broods within each year and the clutches of plural breeds are excluded. Group characteristics refer only to genotyped groups. 
sired by a dominant male in another group, 27 (20.77\%) were sired by a subordinate male in another group and three (2.31\%) were sired by a subordinate male within their social group.

Both male and female auxiliaries had stepwise, negative effects on the percentage of extrapair paternity within a nest. Groups with one, two or more male auxiliaries had significantly fewer extrapair young than groups with no male auxiliaries, however, there was no significant difference between groups with one male auxiliary and groups with two or more male auxiliaries (ANOVA: $P=0.005$, pairwise Bonferroni corrected: zero versus one auxiliary: $P=0.02$; zero versus two or more auxiliaries: $P=0.03$; one versus two or more auxiliaries: $P=1.00$ ). Groups with one female auxiliary had significantly fewer extrapair young than groups with no female auxiliaries, however, there was no significant difference between groups with zero female auxiliaries and groups with two or more female auxiliaries (ANOVA: $P=0.04$, pairwise Bonferroni corrected: zero versus one auxiliary: $P=0.05$; zero versus two or more auxiliaries: $P=0.54$; one versus two or more auxiliaries: $P=1.00$ ). Because of these results, we only examine the presence or absence of auxiliaries in within-nest models.

The presence or absence of extrapair young in a nest was best described by a model retaining the factors presence or absence of male auxiliaries, brood size and presence or absence of female auxiliaries. Presence of male auxiliaries had a significant negative effect on the presence of extrapair young, presence of female auxiliaries had a marginal negative effect and brood size had a marginal positive effect (GLMM, binomial: marginal $R^{2}=0.15$, conditional $R^{2}=0.26$; $\operatorname{AICc}=169.47$, $N_{\text {broods }}=120$; presence or absence of male auxiliaries: $z_{7}=-2.85$, $P \leq 0.01$; brood size: $Z_{7}=1.56, P=0.12$; presence or absence of male auxiliaries brood size: $z_{7}=-1.44, P=0.15$; see Table 3 for model comparisons, Table 4 for model comparisons and model parameters). The percentage of extrapair young in a brood was best explained by a model containing only the fixed effect presence or absence of male auxiliaries, in which the presence of male auxiliaries was negatively correlated with the percentage of extrapair young (GLMM, binomial: marginal $R^{2}=0.09$, conditional $R^{2}=0.64 ; \mathrm{AICc}=302.94 ; N_{\text {broods }}=120$; presence or absence of male auxiliaries: $z_{7}=-3.10, P \leq 0.01$; see Table 3 for model comparisons, see Table 4 for final model parameters). However, this model was not significantly better than the next-best model, which also included 
Table 3 Results from GLMM models examining presence or absence of extrapair young (binomial) and the percentage of extrapair young (binomial), as well as male paternity, including percentage of offspring sired by dominant males within pair (binomial), number of extrapair offspring sired by dominant males (Poisson), total young sired by dominant breeding males (Poisson) and number of offspring sired by auxiliary males (Poisson) in variegated fairy-wren nests sampled between 2012 and 2015

\begin{tabular}{|c|c|c|c|c|c|}
\hline Model & Parameter & Estimate $\pm S E$ & Variance $\pm S D$ & $z$ & $P$ \\
\hline \multicolumn{6}{|c|}{ Extrapair young (presence or absence) } \\
\hline \multirow{4}{*}{ Best-fit model } & Intercept & $1.31 \pm 1.13$ & & 1.16 & 0.25 \\
\hline & Male auxiliaries $(\mathrm{Y} / \mathrm{N})$ & $-1.23 \pm 0.43$ & & -2.85 & $\leq 0.01^{\mathrm{a}}$ \\
\hline & Brood size & $0.51 \pm 0.32$ & & 1.56 & 0.12 \\
\hline & Female auxiliaries $(\mathrm{Y} / \mathrm{N})$ & $-0.31 \pm 0.21$ & & -1.44 & 0.15 \\
\hline \multirow[t]{5}{*}{ Random terms } & Group/social father & & $3.3 \times 10^{-4} \pm 0.02$ & & \\
\hline & Group/mother & & $0.45 \pm 0.67$ & & \\
\hline & Group & & $9.3 \times 10^{-4} \pm 0.03$ & & \\
\hline & Group.1 & & $1.3 \times 10^{-3} \pm 0.04$ & & \\
\hline & Year & & $1.2 \times 10^{-4} \pm 0.01$ & & \\
\hline \multirow[t]{3}{*}{ Rejected terms } & Relatedness between breeding pair & $0.73 \pm 1.23$ & & 0.52 & 0.55 \\
\hline & Group ID & $0.00 \pm 0.00$ & & & \\
\hline & Year & $0.00 \pm 0.00$ & & & \\
\hline \multicolumn{6}{|c|}{ Percentage of extrapair young } \\
\hline \multirow[t]{2}{*}{ Best-fit model } & Intercept & $1.63 \pm 0.84$ & & 1.95 & $0.05^{\mathrm{a}}$ \\
\hline & Male auxiliaries (Y/N) & $-1.66 \pm 0.54$ & & -3.10 & $\leq 0.01^{\mathrm{a}}$ \\
\hline \multirow[t]{5}{*}{ Random terms } & Group/social father & & $0.57 \pm 0.75$ & & \\
\hline & Group/mother & & $4.67 \pm 2.16$ & & \\
\hline & Group & & $2.44 \times 10^{-9} \pm 4.94 \times 10^{-5}$ & & \\
\hline & Group.1 & & $0.00 \pm 0.00$ & & \\
\hline & Year & & $2.84 \times 10^{-15} \pm 5.33 \times 10^{-8}$ & & \\
\hline \multirow[t]{2}{*}{ Rejected terms } & Female auxiliaries $(\mathrm{Y} / \mathrm{N})$ & $-0.36 \pm 0.25$ & & -1.42 & 0.16 \\
\hline & Relatedness between breeding pair & $-0.01 \pm 1.64$ & & -0.01 & 0.99 \\
\hline \multicolumn{6}{|c|}{ Number of offspring sired within-pair by dominant males } \\
\hline \multirow[t]{2}{*}{ Best-fit model } & Intercept & $0.001 \pm 0.40$ & & 0.004 & 0.99 \\
\hline & Male auxiliaries $(\mathrm{Y} / \mathrm{N})$ & $1.39 \pm 0.53$ & & 2.64 & $\leq 0.01^{\mathrm{a}}$ \\
\hline \multirow[t]{5}{*}{ Random terms } & Group/social father & & $0.00 \pm 0.00$ & & \\
\hline & Group/mother & & $5.31 \pm 2.31$ & & \\
\hline & Group & & $0.00 \pm 0.00$ & & \\
\hline & Group.1 & & $0.00 \pm 0.00$ & & \\
\hline & Year & & $0.00 \pm 0.00$ & & \\
\hline \multirow[t]{2}{*}{ Rejected terms } & Female helpers $(\mathrm{Y} / \mathrm{N})$ & $0.54 \pm 0.49$ & & 1.10 & 0.27 \\
\hline & Relatedness of dominant male to social mate & $-0.66 \pm 1.60$ & & -0.41 & 0.68 \\
\hline \multicolumn{6}{|c|}{ Number of extrapair young sired by dominant males } \\
\hline \multirow[t]{2}{*}{ Best-fit model } & Intercept & $-1.05 \pm 0.24$ & & -4.35 & $\leq 0.01^{\mathrm{a}}$ \\
\hline & Number of male auxiliaries & $0.36 \pm 0.16$ & & -2.28 & $0.02^{\mathrm{a}}$ \\
\hline \multirow[t]{5}{*}{ Random terms } & Group/social father & & $0.33 \pm 0.58$ & & \\
\hline & Group/mother & & $0.64 \pm 0.80$ & & \\
\hline & Group & & $0.00 \pm 0.00$ & & \\
\hline & Group.1 & & $0.00 \pm 0.00$ & & \\
\hline & Year & & $0.00 \pm 0.00$ & & \\
\hline \multirow[t]{3}{*}{ Rejected terms } & Number of within-group young & $-0.11 \pm 0.11$ & & -0.97 & 0.33 \\
\hline & Number of female auxiliaries & $-0.13 \pm 0.23$ & & -0.54 & 0.59 \\
\hline & Relatedness of dominant male to social mate & $-0.43 \pm 0.91$ & & -0.48 & 0.63 \\
\hline
\end{tabular}


Table 3 (continued)

\begin{tabular}{|c|c|c|c|c|c|}
\hline Model & Parameter & Estimate $\pm S E$ & Variance $\pm S D$ & $z$ & $P$ \\
\hline \multicolumn{6}{|c|}{ Number of total young sired by dominant males } \\
\hline Best-fit model & Intercept & $0.74 \pm 0.07$ & & 10.67 & $\leq 0.01^{\mathrm{a}}$ \\
\hline \multirow[t]{5}{*}{ Random terms } & Group/social father & & $3.77 \times 10^{-10} \pm 1.94 \times 10^{-5}$ & & \\
\hline & Group/breeding female & & $1.19 \times 10-4 \pm 0.01$ & & \\
\hline & Group & & $1.98 \times 10^{-10} \pm 1.41 \times 10^{-5}$ & & \\
\hline & Group.1 & & $1.31 \times 10^{-10} \pm 1.45 \times 10^{-5}$ & & \\
\hline & Year & & $0.00 \pm 0.00$ & & \\
\hline \multirow[t]{3}{*}{ Rejected terms } & Number of male helpers & $0.06 \pm 0.06$ & & 1.03 & 0.30 \\
\hline & Relatedness of dominant male to social mate & $-0.30 \pm 0.38$ & & -0.81 & 0.42 \\
\hline & Number of female helpers & $0.02 \pm 0.06$ & & 0.23 & 0.82 \\
\hline \multicolumn{6}{|c|}{ Number of total young sired by subordinate males } \\
\hline \multirow[t]{3}{*}{ Best-fit model } & Intercept & $-2.14 \pm 0.56$ & & -3.85 & $\leq 0.01^{\mathrm{a}}$ \\
\hline & Number of female auxiliaries & $0.42 \pm 0.25$ & & 0.25 & 0.09 \\
\hline & Average relatedness to breeding pair & $-1.97 \pm 1.44$ & & -1.37 & 0.17 \\
\hline \multirow[t]{3}{*}{ Random terms } & Group/subordinate male & & $1.36 \pm 1.18$ & & \\
\hline & Group & & $3.75 \times 10^{-8} \pm 1.94 \times 10^{-4}$ & & \\
\hline & Year & & $5.54 \times 10^{-10} \pm 2.35 \times 10^{-5}$ & & \\
\hline Rejected terms & Number of male auxiliaries & $-0.04 \pm 0.20$ & & -0.17 & 0.86 \\
\hline
\end{tabular}

a. $P \leq 0.05$

the fixed effect presence or absence of female auxiliaries (GLMM, binomial: marginal $R^{2}=0.09$, conditional $R^{2}=0.64$, AICc $=303.22$; presence or absence of female auxiliaries: $z_{8}=-1.42 P=0.16$; presence or absence of male auxiliaries: $z_{8}=-2.78 P \leq 0.01$; Table 4 , Fig. 1 ).

\section{Effect of Group Composition on Male Paternity Success}

Dominant males sired more young within their nest when there were male auxiliaries in their group than when there were not (GLMM, binomial: marginal $R^{2}=0.05$, conditional $R^{2}=0.64$; $\mathrm{AICc}=304.25$; $N_{\text {unique males }}=96, N_{\text {male-years }}=120$; presence or absence of male auxiliaries: $z_{7}=2.64, P \leq 0.01$; Table 4, Fig. 2 a). However, this model was not significantly better than the next-best model, which also included the fixed effect presence or absence of female auxiliaries (GLMM, binomial: marginal $R^{2}=0.06$, conditional $R^{2}=0.64$; $\mathrm{AICc}=305.35$; presence or absence of female auxiliaries: $z_{8}=1.10 P=0.27$; presence or absence of male auxiliaries: $z_{8}=2.38 P=0.02$; Table 4).

The best-fitting model explaining the number of extrapair young sired by dominant males contained only the fixed effect number of male auxiliaries. The number of extrapair young sired by dominant males was 
Table 4 Model formula and AICc values from GLMMs examining presence or absence of extrapair young (binomial), percentage of extrapair young (binomial), percentage of offspring sired by dominant males within pair (binomial), number of extrapair offspring sired by dominant males (Poisson), total young sired by dominant breeding males (Poisson) and number of offspring sired by auxiliary males (Poisson) in variegated fairy-wren nests sampled between 2012 and 2015

Models

tested Model formula $\quad$ AICC

Extrapair young (presence or absence) within nest

1. $\sigma^{x}$ auxiliaries $(\mathrm{Y} / \mathrm{N})+$ Brood size $+q$ auxiliaries $(\mathrm{Y} / \mathrm{N}) \quad 169.52$

2. $\sigma^{\text {a }}$ auxiliaries $(\mathrm{Y} / \mathrm{N})+$ Brood size $+q$ auxiliaries $(\mathrm{Y} / \mathrm{N})+$ Relatedness

between breeding pair $\quad 9 \quad 171.58$

3. Null

$6 \quad 177.52$

Percentage of extrapair young within nest

\begin{tabular}{|c|c|c|c|}
\hline 1. & $\sigma^{7}$ auxiliaries $(\mathrm{Y} / \mathrm{N})$ & 7 & 302.94 \\
\hline 2. & $\sigma^{\prime}$ auxiliaries $(\mathrm{Y} / \mathrm{N})+q$ auxiliaries $(\mathrm{Y} / \mathrm{N})$ & 8 & 303.22 \\
\hline 3. & 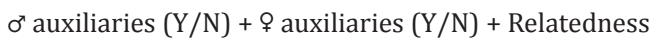 & & \\
\hline & between breeding pair & 9 & 305.56 \\
\hline & Null & 6 & 310.80 \\
\hline
\end{tabular}

Number of offspring sired within-pair by dominant males

1. $\sigma^{7}$ auxiliaries $(\mathrm{Y} / \mathrm{N}) \quad 304.25$

2. $\sigma^{7}$ auxiliaries $(\mathrm{Y} / \mathrm{N})+q$ auxiliaries $(\mathrm{Y} / \mathrm{N}) \quad 305.35$

3. $\sigma^{x}$ auxiliaries $(\mathrm{Y} / \mathrm{N})+q$ auxiliaries $(\mathrm{Y} / \mathrm{N})+$ Relatedness

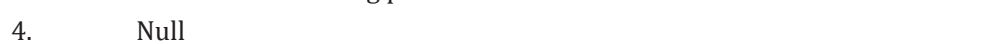

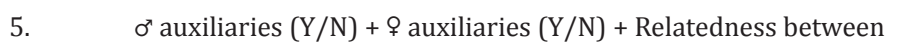
$\begin{array}{lll}\text { breeding pair + No. of extrapair young sired } & 10 & 309.79\end{array}$

\section{Number of extrapair young sired by dominant males}

$\begin{array}{llll}\text { 1. No. } o^{\text {a auxiliaries }} & 7 & 400.33\end{array}$

2. No. ơ auxiliaries + No. of within-pair young sired $\quad 8 \quad 401.54$

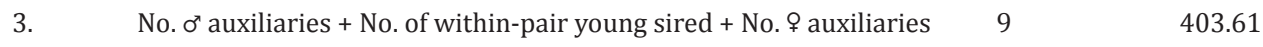

4. Null $\quad 6 \quad 403.72$

5. $\quad$ No. $0^{\pi}$ auxiliaries + No. of within-pair young sired + No. 9 auxiliaries

+ Relatedness between breeding pair $\quad 10 \quad 405.47$

Number of total young sired by dominant males

\begin{tabular}{|c|c|c|c|}
\hline 1. & Null & 6 & 429.96 \\
\hline 2. & No. $o^{\top}$ auxiliaries & 7 & 431.19 \\
\hline 3. & No. $\sigma^{\top}$ auxiliaries + Relatedness between breeding pair & 8 & 432.82 \\
\hline 4. & $\begin{array}{l}\text { No. } \sigma^{7} \text { auxiliaries + Relatedness between breeding pair + } \\
\text { No. } ९ \text { auxiliaries }\end{array}$ & 9 & 435.11 \\
\hline \multicolumn{4}{|c|}{ Number of total young sired by subordinate males } \\
\hline 1. & No. $\$$ auxiliaries + Relatedness to breeding pair & 6 & 170.63 \\
\hline 2. & No. $\$$ auxiliaries & 5 & 170.69 \\
\hline 3. & Null & 4 & 171.00 \\
\hline 4. & No. $\$$ auxiliaries + Relatedness to breeding pair + No. $\sigma^{x}$ auxiliaries & 7 & 172.80 \\
\hline
\end{tabular}




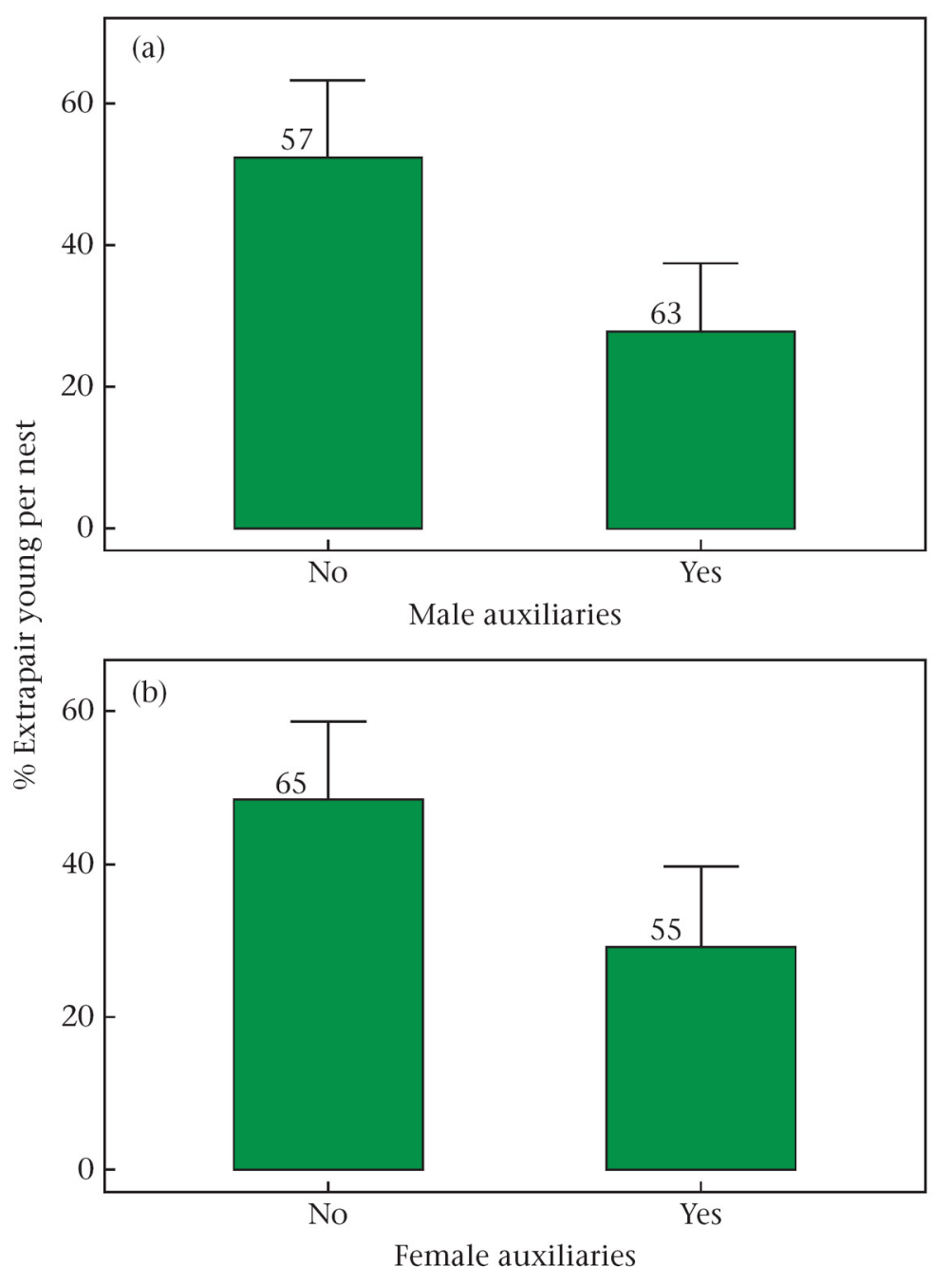

Figure 1. Average percentage of extrapair offspring per nest in relation to (a) the number of male auxiliaries and (b) the number of female auxiliaries in the social group. Error bars represent $95 \%$ confidence intervals.

negatively correlated with the number of male auxiliaries present in the dominant male's social group (GLMM, Poisson: marginal $R^{2}=0.05$, conditional $R^{2}=0.41 ; \mathrm{AICc}=400.33 ; N_{\text {unique males }}=131, N_{\text {male-years }}=210$; number of male auxiliaries: $z_{7}=-2.28, P=0.02$; Table 4 , Fig. $2 \mathrm{~b}$ ). However, this model was not significantly better than the next-best model, which also included the fixed effect number of within-pair young (GLMM, Poisson: marginal $R^{2}=0.06$, conditional $R^{2}=0.41 ; \mathrm{AICc}=401.54 ;$ number of within-pair young: $z_{8}=-0.97 P=0.33$; number of male auxiliaries: $z_{8}=$ $-2.18 P=0.03$; Table 4). 

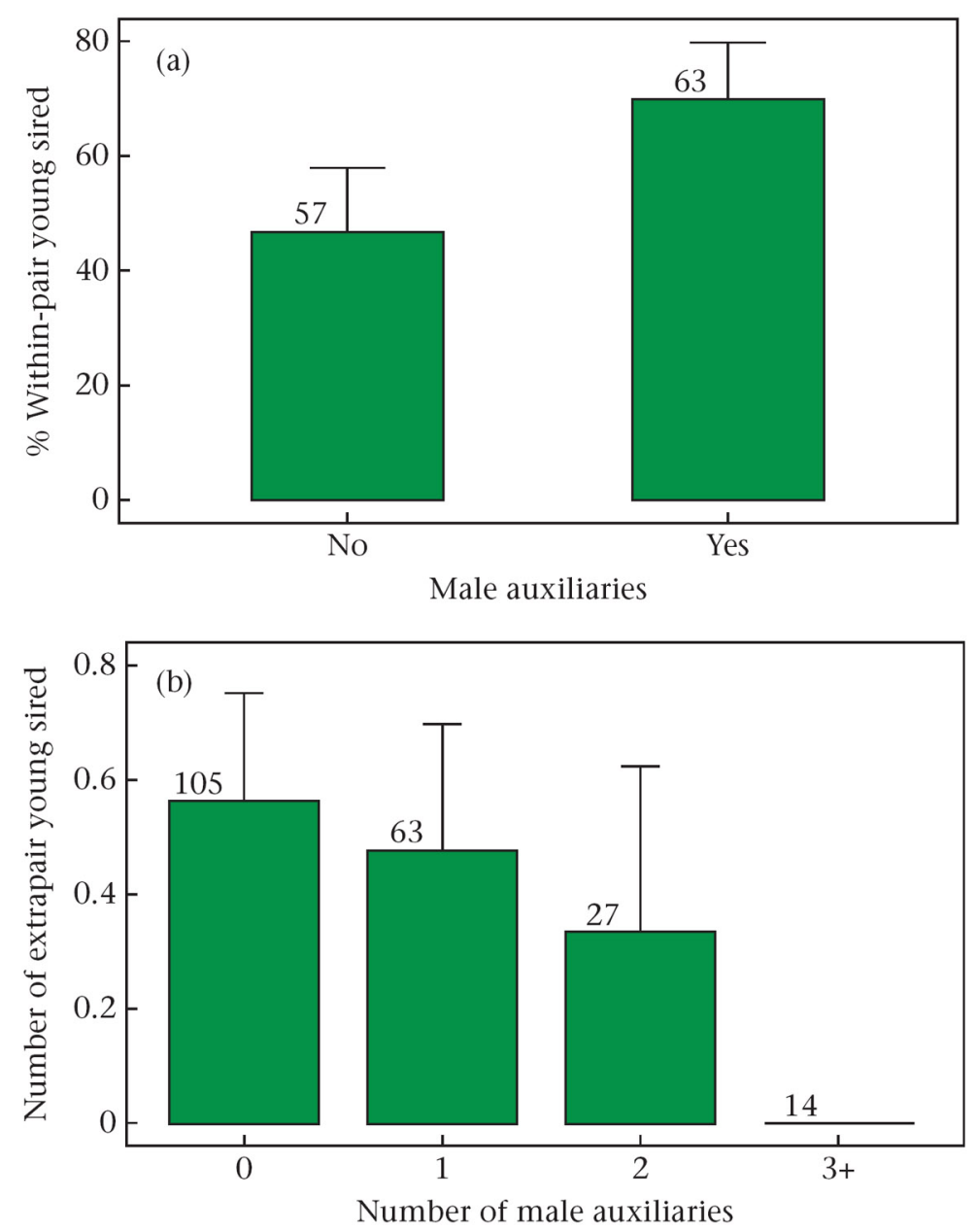

Figure 2. Reproductive success of dominant males based on (a) the percentage of within-pair young sired (includes only dominant males whose nests were sampled) and (b) the number of extrapair young sired in relation to the presence or absence of male auxiliaries, and the number of male auxiliaries present in their social group (also see Table 4). Error bars represent 95\% confidence intervals.

The total number of young sired by dominant males was best explained by the null model (GLMM, Poisson: marginal $R^{2}=0$, conditional $R^{2}=0.65 ;$ AICc $=429.96 ; N_{\text {unique males }}=96, N_{\text {male years }}=120$; Table 4 ).

The best-fitting model explaining the variation in total number of young (within or outside of social group) sired by auxiliary males contained the fixed effects number of female helpers and average relatedness to the breeding pair (GLMM, Poisson: marginal $R^{2}=0.31$, conditional $R^{2}=0.57 ; \mathrm{AICc}=170.63 ; N_{\text {unique males }}=123, N_{\text {male-years }}=147$; number of female auxiliaries: $z_{6}=1.68, P=0.09$; average relatedness to breeding 
pair: $z_{6}=-1.37, P=0.17$; Table 4 ). However, this model did not significantly differ from the null model (GLMM, Poisson: marginal $R^{2}=0.02$, conditional $\left.R^{2}=0.40 ; \mathrm{AICc}=171.00\right)$.

\section{Discussion}

Reproductive promiscuity in variegated fairy-wrens was moderate compared with other fairy-wren species, with 39\% of young sired by extrapair males. While the proportion of broods containing extrapair young was relatively high, the distribution of extrapair young differed from that observed in other fairy-wren species. Strikingly, rather than exhibiting higher rates of extrapair paternity in groups with auxiliaries, as observed in red-winged, Malurus elegans, splendid, superb and red-backed fairywrens (Brouwer et al., 2017; Mulder et al., 1994; Webster et al., 2004), variegated fairy-wrens have lower rates of extrapair paternity per nest with increased group size. Based on the comparative analysis of Brouwer et al. (2017), the variegated fairy-wren is the only species of Malurus to show this trend, within a single population. Comparing different populations of superb fairy-wren, there is a suggestion of a similar trend, if not as striking (Brouwer et al., 2017).

Rates of extrapair paternity have been found to correlate positively with relatedness of the breeding pair in the red-winged fairy-wren and splendid fairy-wren, as well as generally across malurid species (Brooker, Rowley, Adams, \& Baverstock, 1990; Brouwer et al., 2011, 2017; Tarvin et al., 2005). In such cases, extrapair paternity is hypothesized to function as an inbreeding avoidance mechanism. Analysis of our data by Brouwer et al. (2017), in which the relatedness of the social pair was considered to be either incestuous or not, showed a similar result: incestuous pairs had a greater proportion of extrapair young (Figure 2D in Brouwer et al., 2017). In that study, an incestuous pair was defined as a pair in which relatedness was within the range of the mean \pm 1.5 SD of first-order relatives. Nevertheless, our inclusion of relatedness values as a continuous variable indicated that it had a negligible impact on extrapair paternity. Relatedness between the socially paired (dominant) male and female did not predict either the presence of extrapair young, or the number of extrapair young in a nest. Furthermore, while male auxiliaries sired $\sim 20 \%$ of extrapair young, their reproductive 
success was not predicted either by their relatedness to the breeding pair within their social group, or by the number of other male or female auxiliaries in their social group. Both in terms of the rate of extrapair paternity across nests and variation in paternity by the breeding male, the presence of male auxiliaries had a greater effect on extrapair paternity rates than the presence of female auxiliaries. Dominant males sired a greater percentage of young within their nests when male auxiliaries were present, and to a lesser degree, when female auxiliaries were present. This could result from several scenarios. First, dominant males in groups with auxiliaries may be of higher quality, either because they have sired successful young in the past (as demonstrated by auxiliary group members) or because they defend high-quality territories capable of sustaining a multibird group. However, if social male quality alone contributes to a low rate of extrapair paternity within a nest, we may also expect those males to sire more extrapair young than males without auxiliaries. However, we observed the opposite pattern. Second, auxiliaries may help the dominant male defend the breeding female from intruders, or they may accompany the female on extraterritory forays, reducing her ability to engage in extrapair copulations. This behavior is expected when auxiliaries are related to the breeding pair and when extrapair offspring are of somewhat higher viability than within-pair offspring (Welbergen \& Quader, 2006). Dominant male red-backed fairywrens have been observed to decrease mate-guarding behaviors in the presence of auxiliaries (Potticary, Dowling, Barron, Baldassarre, \& Webster, 2016). We observed similar behavior in variegated fairy-wrens, in which dominant males with auxiliaries (typically males) engaged in extraterritory forays more often, leaving the auxiliaries to accompany the breeding female. Third, breeding males may be more active in defending their social mate when male auxiliaries are present because auxiliary males may vie with dominant males for access to the breeding female. Such behavior has been observed in other cooperative breeders in which the primary source of extrapair paternity is within groups (Mumme, Koenig, \& Pitelka, 1983). Subordinate males sired 20\% of extrapair young in the variegated fairy-wren, however, only $\sim 2 \%$ were sired by group members, suggesting this may not be a viable hypothesis for this species.

Finally, dominant males or females may use different reproductive strategies depending on whether they are in groups with or without 
auxiliaries. Helping behavior across cooperatively breeding species is highly variable both in the amount of aid offered and in which individuals offer aid (Komdeur, 1994; Legge, 2000). In variegated fairy-wrens, male auxiliaries are more likely to provision and provision more often than female auxiliaries (Johnson, 2016; Johnson \& Pruett-Jones, 2017). The presence of helpers also significantly increases the likelihood that a nest will fledge young, with $51 \%$ of groups with auxiliaries fledging young versus $26 \%$ of groups without auxiliaries fledging young (Johnson, 2016; Johnson \& Pruett-Jones, 2017). Groups without auxiliaries often lose young to starvation, suggesting that provisioning by auxiliaries may significantly contribute to increased nest success found in larger groups (A. E. Johnson, personal observation). Dominant males may put more effort into defending their social mate from extrapair suitors rather than engaging in extrapair copulations because a nest with auxiliaries present is more likely to successfully fledge young. Females in these groups may avoid extrapair copulations to avoid the loss of auxiliary investment if group relatedness decreases.

A variable reproductive strategy may also explain why dominant males in groups with auxiliary males had fewer extrapair young than dominant males in groups without auxiliary males. Dominant males in groups without male auxiliaries may be reproductively bet hedging; with low confidence of nest success, they may seek other reproductive opportunities to increase or salvage that year's fecundity. This has been suggested as one of the factors affecting conspecific brood parasitism by female birds (Lyon \& Eadie, 2008). Interestingly, the presence of auxiliaries did not impact the total reproductive success of dominant breeding males. Females in groups without auxiliaries may seek extrapair suitors to increase the genetic diversity of their clutch and increase the likelihood that one or more nestlings will survive.

Our findings are consistent with the monogamy hypothesis of cooperative breeding (Cornwallis et al., 2010), but suggest that extrapair paternity may be highly flexible depending on the social environment. Variegated fairy-wrens, like other cooperatively breeding taxa, may exhibit low extrapair paternity when helping behavior is present, however, they still exhibit relatively high rates of extrapair paternity. Variegated fairy-wrens may use extrapair paternity as an alternative breeding strategy when auxiliaries are not present. As observed in other species, we have shown that group composition rather than group size alone, 
contributes significantly to variation in extrapair paternity across social groups (Brouwer, van de Pol, \& Cockburn, 2014; Koenig, Walters, \& Haydock, 2011; Legge, 2000; Lejeune, van de Pol, Cockburn, Louter, \& Brouwer, 2016).

Why does the pattern of extrapair paternity in variegated fairy-wrens differ so drastically from that found in other fairy-wren species? Work by Colombelli-Négrel et al. (2009) in one population of superb fairy-wrens found high levels of extrapair paternity (67\% of nestlings) even though the population had few auxiliaries, suggesting that either female release is not driving extrapair paternity in this species, or perhaps that auxiliary helping behavior may be less necessary in some fairy-wren species. Studies of the purple-crowned fairy-wren, Malurus coronatus, a species with higher average numbers of auxiliary group members than superb, splendid, or red-backed fairy-wrens, documented extraordinarily low rates of extrapair paternity (4.4\% of offspring; Kingma, Hall, Arriero, \& Peters, 2010; Kingma et al., 2009). It was further found that auxiliaries contributed significantly to provisioning at the nests, and the authors suggested that the low rates of extrapair paternity in this species are linked to kin-selected benefits of helping behavior (Kingma et al., 2009, 2010). Recent work by Brouwer et al. (2017) suggests that multiple different hypotheses contribute to variation in extrapair paternity across the Maluridae. In combination with other work, our study suggests that fairy-wrens may be atypical cooperative breeders in terms of their group composition and high levels of extrapair paternity.

More empirical work is needed in the variegated fairy-wren to understand what drives mate choice in females engaging in extrapair copulations, to elucidate whether auxiliary males in fact gain inclusive fitness benefits by investing in nondescendent young and to explain why auxiliary sex matters for both breeding individuals and auxiliary behavior. However, the results of the present study provide additional evidence that studies of cooperative breeding should include group composition when considering the role of auxiliaries in group behavior, and that while many cooperative systems are being studied, studies of new taxa are still important in developing our understanding of why variation in cooperative breeding exists and how cooperative breeding behavior evolves. 
Acknowledgments We thank the following people and institutions. T. Price, J. Mateo, T. Wootton, J. Bates, M. B. Brown, B. Gallagher, J. Mitchell and two anonymous referees commented on statistical analysis and helped revise the manuscript. N. Desmarais, E. Geary, I. Hoppe, E. Kinnebrew, C. Masco, D. Meyer, A. Rummel, Y. Ren, J. Uehling, K. Urban and P. Zaykoski provided assistance and support in the field. E. Kinnebrew, D. Meyer and J. Uehling also helped in the laboratory. Conservation Volunteers Australia (especially T. Curtis and T. Peacock) provided access to Brookfield Conservation Park and on site assistance. A.E.J. was funded through the University of Chicago.

\section{References}

Bates, D., Mächler, M., Bolker, B., \& Walker, S. (2015). Fitting linear mixed-effects models using lme4. Journal of Statistical Software, 67, 1-48.

Boland, C., \& Cockburn, A. (2002). Short sketches from the long history of cooperative breeding in Australian birds. Emu, 102, 9-17.

Boomsma, J. J. (2009). Lifetime monogamy and the evolution of eusociality. Philosophical Transactions of the Royal Society B, 364, 3191-3207.

Boomsma, J. J. (2013). Beyond promiscuity: Mate-choice commitments in social breeding. Philosophical Transactions of the Royal Society B, 368, 20120050.

Brooker, M. G., Rowley, I., Adams, M., \& Baverstock, P. R. (1990). Promiscuity: An inbreeding avoidance mechanism in a socially monogamous species. Behavioral Ecology and Sociobiology, 26, 191-199.

Brouwer, L., van de Pol, M., Aranzamendi, N. H., Bain, G., Baldassare, D. T., Brooker, L. C., et al. (2017). Multiple hypotheses explain variation in extra-pair paternity at different levels in a highly variable avian family. Molecular Ecology, 26, 6717-6729.

Brouwer, L., van de Pol, M., Atema, E., \& Cockburn, A. (2011). Strategic promiscuity helps avoid inbreeding at multiple levels in a cooperative breeder where both sexes are philopatric. Molecular Ecology, 20, 4796-4807.

Brouwer, L., van de Pol, M., \& Cockburn, A. (2014). The role of social environment on parental care: Offspring benefit more from the presence of female than male helpers. Journal of Animal Ecology, 83, 491-503.

Brown, J. L. (1987). Helping and communal breeding in birds: Ecology and evolution. Princeton, NJ: Princeton University Press.

Browning, L. E., Patrick, S. C., Rollins, L. A., Griffith, S. C., \& Russell, A. F. (2012). Kin selection, not group augmentation, predicts helping in an obligate cooperatively breeding bird. Proceedings of the Royal Society B: Biological Sciences, 279, 3861-3869.

Cockburn, A. (1998). Evolution of helping behavior in cooperatively breeding birds. Annual Review of Ecology and Systematics, 29, 141-177.

Cockburn, A., Brouwer, L., Double, M. C., Margraf, N., \& van de Pol, M. (2013). Evolutionary origins and persistence of infidelity in Malurus: The least faithful birds. Emu, 113, 208-217. 
Colombelli-Négrel, D., Schlotfeldt, B. E., \& Kleindorfer, S. (2009). High levels of extrapair paternity in superb fairy-wrens in South Australia despite low frequency of auxiliary males. Emu, 109, 300-304.

Cornwallis, C. K., West, S. A., Davis, K. E., \& Griffin, A. S. (2010). Promiscuity and the evolutionary transition to complex societies. Nature, 466, 969-972.

Cornwallis, C. K., West, S. A., \& Griffin, A. S. (2009). Routes to indirect fitness in cooperatively breeding vertebrates: Kin discrimination and limited dispersal. Journal of Evolutionary Biology, 22, 2445-2457.

Department for Environment and Heritage. (2005). Brookfield conservation park management plan. Adelaide, South Australia: Department for Environment and Heritage, Government of South Australia. http://www.environment.sa.gov.au/ parks/pdfs/brookfield mp.pdf

Double, M. C., Dawson, D., Burke, T., \& Cockburn, A. (1997). Finding the fathers in the least faithful bird: A microsatellite-based genotyping system for the superb fairywren Malurus cyaneus. Molecular Ecology, 6, 691-693.

Dunn, P. O., \& Cockburn, A. (1996). Evolution of male parental care in a bird with almost complete cuckoldry. Evolution, 50, 2542-2548.

Dunn, P. O., Cockburn, A., \& Mulder, R. A. (1995). Fairy-wren helpers often care for young to which they are unrelated. Proceedings of the Royal Society B, 259, 339-343.

Emlen, S. T. (1991). Evolution of cooperative breeding in birds and mammals. In J. R. Krebs, \& N. B. Davies (Eds.), Behavioral ecology: An evolutionary approach (3rd ed., pp. 301-337). U.K.: Blackwell: Oxford.

Fitzpatrick, J. W., \& Bowman, R. (2016). Florida scrub-jays: Oversized territories and group defense in a fire-maintained habitat. In W. D. Koenig, \& J. L. Dickinson (Eds.), Cooperative breeding in vertebrates (pp. 77-96). Cambridge, U.K.: Cambridge University Press.

Green, J. P., Freckleton, R. P., \& Hatchwell, B. J. (2016). Variation in helper effort among cooperatively breeding bird species is consistent with Hamilton's rule. Nature Communications, 7, 12663.

Griffin, A. S., Pemberton, J. M., Brotherton, P. N. M., McIlrath, G., Gaynor, D., Kransky, R., O'Riain, J., \& Clutton-Brock, T. H. (2003). A genetic analysis of breeding success in the cooperative meerkat (Suricata suricatta). Behavioral Ecology, 14, 472-480.

Haig, S. M., Belthoff, J. R., \& Allen, D. H. (1993). Examination of population structure in red-cockaded woodpeckers using DNA profiles. Evolution, 47, 185-194.

Haig, S. M., Walters, J. R., \& Plissner, J. H. (1994). Genetic evidence for monogamy in the cooperatively breeding red-cockaded woodpecker. Behavioral Ecology and Sociobiology, 34, 295-303.

Hamilton, W. D. (1964). The genetical evolution of social behaviour. I. Journal of Theoretical Biology, 7, 1-16.

Hatchwell, B. J., Gullett, P. R., \& Adams, M. J. (2014). Helping in the cooperatively breeding long-tailed tits: A test of Hamilton's rule. Philosophical Transactions of the Royal Society B, 369, 20130565.

Johnson, A. E. (2016). Evolution and sociality in fairy-wrens (Aves: Maluridae) (Doctoral dissertation). Chicago, IL: University of Chicago. 
Johnson, A. E., \& Pruett-Jones, S. (2017). Cooperative breeding in the variegated fairy-wren: Effects of social environment on nestling provisioning and survival (Manuscript submitted for publication).

Kalinowski, S. T., Taper, M. L., \& Marshall, T. C. (2007). Revising how the computer program CERVUS accommodates genotyping error increases success in paternity assignment. Molecular Ecology, 16, 1099-1106.

Kalinowski, S. T., Wagner, A. P., \& Taper, M. L. (2006). ML-relate: A computer program for maximum likelihood estimation of relatedness and relationship. Molecular Ecology Notes, 6, 576-579.

Karubian, J. (2002). Costs and benefits of variable breeding plumage in the redbacked fairy-wren. Evolution, 56, 1673-1682.

Kingma, S. A., Hall, M. L., Arriero, E., \& Peters, A. (2010). Multiple benefits of cooperative breeding in purple-crowned fairy-wrens: A consequence of fidelity? Journal of Animal Ecology, 79, 757-768.

Kingma, S. A., Hall, M. L., Segelbacher, G., \& Peters, A. (2009). Radical loss of an extreme extra-pair system. BMC Ecology, 9, 15.

Koenig, W. D., Pitelka, F. A., Carmen, W. J., Mumme, R. L., \& Stanback, M. T. (1992). The evolution of delayed dispersal in cooperative breeders. Quarterly Review of Biology, 67, 111-150.

Koenig, W. D., Walters, E. L., \& Haydock, J. (2011). Variable helper effects, ecological condition and the evolution of cooperative breeding in the acorn woodpecker. American Naturalist, 178, 145-158.

Komdeur, J. (1994). The effect of kinship on helping in the cooperative breeding Seychelles warbler (Acrocephalus sechellensis). Proceedings of the Royal Society B, $256,47-52$.

Legge, S. (2000). The effect of helpers on reproductive success in the laughing kookaburra. Journal of Animal Ecology, 69, 714-724.

Lejeune, L., van de Pol, M., Cockburn, A., Louter, M., \& Brouwer, L. (2016). Male and female helper effects on maternal investment and adult survival in red-winged fairy-wrens. Behavioral Ecology, 27, 1841-1850.

Lukas, D., \& Clutton-Brock, T. (2012). Cooperative breeding and monogamy in mammalian societies. Proceedings of the Royal Society B, 279, 2151-2156.

Lyon, B. E., \& Eadie, J. M. (2008). Conspecific brood parasitism in birds: A life history perspective. Annual Review of Ecology, Evolution, and Systematics, 39, 343-363.

MacColl, A. D. C., \& Hatchwell, B. J. (2002). Temporal variation in fitness pay-offs promotes cooperative breeding in long-tailed tits Aegithalos caudatus. American Naturalist, 160, 186-194.

Maguire, G. S., Guay, P.-J., \& Mulder, R. A. (2006). Isolation and characterization of microsatellite markers in the southern emu-wren (Stipiturus malachurus: Aves). Molecular Ecology Notes, 6, 422-424.

Margraf, N., \& Cockburn, A. (2013). Helping behavior and parental care in fairywrens (Malurus). Emu, 113, 294-301.

Marshall, T. C., Slate, J., Kruuk, L. E. B., \& Pemberton, J. M. (1998). Statistical confidence for likelihood-based paternity inference in natural populations. Molecular Ecology, 7, 639-655. 
Mulder, R. A., Dunn, P. O., Cockburn, A., Lazenby-Cohen, K. A., \& Howell, M. J. (1994). Helpers liberate female fairy-wrens from constraints on extra-pair mate choice. Proceedings of the Royal Society B, 255, 223-229.

Mumme, R. L. (1992). Do helpers increase reproductive success? An experimental analysis in the Florida scrub jay. Behavioral Ecology and Sociobiology, 31, 319-328.

Mumme, R. L., Koenig, W. D., \& Pitelka, F. A. (1983). Mate guarding in the acorn woodpecker: Within-group reproductive competition in a cooperative breeder. Animal Behaviour, 31, 1094-1106.

Nakagawa, S., \& Schielzeth, H. (2013). A general and simple method for obtaining R2 from generalized linear mixed-effects models. Methods in Ecology and Evolution, 4(2), 133-142.

Pemberton, J. M., Slate, J., Bancroft, D. R., \& Barrett, J. A. (1995). Nonamplifying alleles at microsatellite loci: A caution for parentage and population studies. Molecular Ecology, 4, 249-252.

Potticary, A. L., Dowling, J. L., Barron, D. G., Baldassarre, D. T., \&Webster, M. S. (2016). Subtle benefits of cooperation to breeding males of the red-backed fairy-wren. Auk, 133, 286-297.

Pruett-Jones, S., \& Tarvin, K. A. (2001). Aspects of the ecology and behaviour of white-winged fairy-wrens on Barrow Island. Emu, 101, 73-78.

R Development Core Team. (2016). R: A language and environment for statistical computing. Vienna, Austria: R Foundation for Statistical Computing. http:// www.R-project.org/

Rathburn, M. K., \& Montgomerie, R. (2003). Breeding biology and social structure of white-winged fairy-wrens (Malurus leucopterus): Comparison between island and mainland subspecies having different plumage phenotypes. Emu, 103, 295-306.

Rowley, I., \& Russell, E. (1995). The breeding biology of the white-winged fairy-wren Malurus leucopterus leuconotus in a Western Australian coastal heathland. Emu, 95, 175-184.

Rowley, I., \& Russell, E. (1997). Fairy-wrens and grasswrens, Maluridae. Oxford, U.K.: Oxford University Press.

Rowley, I., Russell, E., Payne, R. B., \& Payne, L. L. (1989). Plural breeding in the splendid fairy-wren, Malurus splendens (Aves: Maluridae), a cooperative breeder. Ethology, 83, 229-247.

Russell, A. F. (2016). Chestnut-crowned babblers: Dealing with climatic adversity and uncertainty in the Australian arid zone. In W. D. Koenig, \& J. L. Dickinson (Eds.), Cooperative breeding in vertebrates (pp. 150-164). Cambridge, U.K.: Cambridge University Press.

Summers, K., \& Amos, W. (1997). Behavioral, ecological, and molecular genetic analyses of reproductive strategies in the Amazonian dart-poison frog, Dendrobates ventrimaculatus. Behavioral Ecology, 83, 229-247.

Tarvin, K. A., Webster, M. S., Tuttle, E. M., \& Pruett-Jones, S. (2005). Genetic similarity of social mates predicts the level of extrapair paternity in splendid fairy-wrens. Animal Behaviour, 70, 945-955. 
Tibbetts, E., \& Pruett-Jones, S. (1999). Habitat and nest-site partitioning in splendid and variegated fairy-wrens (Aves: Maluridae). Australian Journal of Zoology, 47, 317-326.

Tidemann, S. C. (1983). The behavioral ecology of three co-existing fairy-wrens (Maluridae: Malurus) (Ph.D. thesis). Canberra: Australian National University.

Van Bael, S., \& Pruett-Jones, S. (2000). Breeding biology and social behaviour of the eastern race of the splendid fairy-wren Malurus splendens melanotus. Emu, 100, 95-108.

Varian-Ramos, C. W., \& Webster, M. S. (2012). Extrapair copulations reduce inbreeding for female red-backed fairy-wrens, Malurus melanocephalus. Animal Behaviour, 83, 857-864.

Webster, M. S., Tarvin, K. A., Tuttle, E. A., \& Pruett-Jones, S. (2004). Reproductive promiscuity in the splendid fairy-wren: Effects of group size and auxiliary reproduction. Behavioral Ecology, 15, 907-915.

Webster, M. S., Varian-Ramos, C. W., \& Karubian, J. (2008). Plumage color and reproduction in the red-backed fairy-wren: Why be a dull breeder? Behavioral Ecology, 19, 517-524.

Welbergen, J. A., \& Quader, S. (2006). Mother guarding: How offspring may influence the extra-pair behavior of their parents. Proceedings of the Royal Society B, 273, 2363-2368.

West, S. A., Griffin, A. S., \& Gardner, S. (2007). Evolutionary explanations for cooperation. Current Biology, 17, R661-R672. 